\title{
The Diagnostic Role of Hyperbilirubinemia in Complicated and non-complicated Appendicitis.
}

\author{
Valon A. Zejnullahu ${ }^{1}$, Rozalinda Isjanovska ${ }^{1,3}$, Besnik X. Bicaj ${ }^{1}$, Vjosa A. Zejnullahu ${ }^{1}$, Astrit \\ R. Hamza ${ }^{1}$, Viktorija Caloska-Ivanova ${ }^{1 *}$
}

Received: 10 May 2018; Accepted: 30 June 2018; Published online: 20 July 2018.

DOI; https://doi.org/10.32391/ajtes.v2i2.14

\footnotetext{
Abstract

Background: Acute appendicitis is one of the most frequent causes of abdominal pain. Early diagnosis is the key to success for the surgeon, followed by the treatment with operation or conservative treatment as a new approach, before the stage of gangrenous appendicitis or perforation occurs.

Aim: This study aims to establish he role of hyperbilirubinemia as a laboratory marker in prediction of acute appendicitis in the early diagnosis.

Materials and methods: This is a cross-sectional study; it included 201 patients admitted in the emergency ward with suspicion for acute appendicitis. All patients that participated in this study have been subject to appendectomy. The blood samples were taken from all patients in order to analyze the level of total/direct bilirubin.

Results: The study samples of 201 patients consisted of $67.7 \%$ with complicated appendicitis and $32.3 \%$ with non-complicated appendicitis. The sensitivity, specificity, PPV, NPV for laboratory marker, as predictor for complicated vs non-complicated cases of appendicitis was as follows: Total bilirubin; specificity (72.3\%), sensitivity (54.4\%), PPV (80.4\%), NPV (43.1\%), Conclusion: Elevation of total/direct bilirubin level in patients with clinical signs of acute appendicitis might predict the stage of acute appendicitis, such prediction may help surgeons to provide accurate treatment of the disease without delay in the diagnosis. This accuracy can be further supplemented by using Alvarado scoring model during the clinical approach.

Keywords: Acute appendicitis, total/direct bilirubin, appendectomy, examination, clinical approach, Alvarado score.

*Corresponding author: Viktorija Caloska-Ivanov

$\equiv$ E-mail: prof.isjanovska@gmail.com

${ }^{1}$ Department of Abdominal Surgery, University Clinical Centre of Kosova, Prishtina, Kosovo

${ }^{2}$ University Clinic of Gastrohep, Faculty of Medicine, Ss Cyril and Methodius University of Skopje

${ }^{3} \mathrm{MD}$, Ph.D., Professor, Agency for Quality and Accreditation of Healthcare Organizations in R. Macedonia,
} 


\section{Introduction}

Acute appendicitis is defined as an inflammation of the appendix vermiformis. It is a common cause of abdominal pain and still remains a diagnostic and therapeutic challenge for surgeons in the emergency ward. Less than five percent of children diagnosed with acute appendicitis are younger than five (5) years old (1). Up to $40 \%$ of cases with appendicitis occur in the age-group between 10 and 29 years(2). Although, it is frequently seen in second through fourth decades of life, it can be diagnosed in any age. Appendicitis is more frequent in males rather than females (8.6\% vs. $6.7 \%$ ) (3). The common cause of appendicitis is usually obstruction of lumen with nonspecific factors (4, 5).This obstruction occurs from the undigested food, fecaloma, lymphoid inflammation or even any twist around. In a small percentage of cases, bacteria from enteric part may infect appendix with direct spread or may cause hyperplasia in the lymphoid part of appendix with consequent obstruction.(6) More than 14 organisms are reported in patients with perforative appendicitis. Different agents including adenoviruses (Montgomery EA and al) Rubella(8) ,Epstein-Barr virus, Actinomyces Israeli $(8,9)$,Ascaris lumbricoides and Enterobius vermicularis $(10,11)$ are involved in this polymicrobial infection. Escherichia coli and Bacteroides fragilis are two organisms which equally found in normal appendix as well as in acute and perforated appendicitis $(12,13)$. In the later stages of the inflammation, mucosal ulceration occurs, followed by Escherichia coli dissemination to the portal blood system. Studies in animal models have shown that bacteria can interfere with microcirculation on the hepatocyte, thus inducing hepatic damage with impaired acid bile secretion within the hepatobiliary system(14).
E. coli affects also the intravascular hemolysis, second mechanism by which bilirubin levels increase in the blood circulation (15). Recently, the use of imaging methods was associated with increased diagnostic accuracy in daily practice and decreased rate of negative appendectomy.

This way, SCOAP trial with 3540 appendectomies performed, found significant decrease in negative appendectomy with increased CT and ultrasound use(16).

Different scoring systems are available and the most commonly used are: the Alvarado Score, Acute Inflammatory Response Score, the Pediatric Appendicitis Score (PAS) (17) and the Lintula score (18).

The first score was presented by Alvarado in 1986 and furthermore modified Alvarado score was accessible by Kalan and colleagues (19). Their score ranged from 0-9 points.

The use of Alvarado score is important during the clinical evaluation of patient suspicious for acute appendicitis. Every patient with high Alvarado score needs further assessment and evaluation.

There are many systems that numerous authors proposed for use during the clinical assessment of patients with abdominal pain but the Alvarado score with its modification is widely favored (19, 20).

The Alvarado score was constructed by Alvarado in 1986 and is expressed up to maximum10 points. It is also known as a MANTRELS, which is an acronym for Alvarado score (Table 1). 


$\begin{array}{ll}\text { Feature } & \text { Point } \\ \text { Migration of pain } & 1 \\ \text { Anorexia } & 1 \\ \text { Nausea } & 1 \\ \begin{array}{l}\text { Tenderness in right lower } \\ \text { quadrant }\end{array} & 2 \\ \text { Rebound pain } & 1 \\ \text { Fever } & 1 \\ \text { Leukocytosis } & 2 \\ \text { Shift of white blood cell } & 1 \\ \text { count to the left } & \\ \text { Total } & 10\end{array}$

Table 1: Structural criteria of the Alvarado Score Modified from: Alvarado A. A practical score for the early diagnosis of acute appendicitis. Ann Emerg Med 1986; 15:557.

Scores from 1 to 4 correspond to low risk for acute appendicitis and subsequently patient can be discharged from the Emergency Ward, whether the score from 5 to 6 needs further observation. Finally, in cases when the score is 7 up to 10 ,surgical intervention is considered(20). Currently, the clinical approach for all cases suspicious for acute appendicitis, include CBC (complete blood count) particularly leukocyte count, serum $\mathrm{C}$ - reactive protein and pregnancy test for women in childbearing age, for the purpose of excluding pregnancy.

\section{Differential Diagnosis}

Different inflammatory processes can simulate the acute appendicitis manifestation with similar and overlapping signs and symptoms, such is Meckel's diverticulitis, acute ileitis, cecal diverticulitis, crohn's disease, urologic disorders, gynecologic disorders, tubo-ovarian abscess.

\section{Treatment}

The treatment of acute appendicitis is appendectomy with open approach, appendectomy with laparoscopic approach and non-operative treatment. The operative treatment is widely used for treatment in patients with acute appendicitis. This can be performed with classical operation or laparoscopic approach depending on the experience of surgeon. The newest studies suggest the treatment of non- complicated acute appendicitis with conservative approach. This approach is usually applied in the initial phases of the inflammation and include the use of antibiotics, rehydration and dynamic follow-up. $(21,22)$. Acute appendicitis without complication can be managed successfully with antibiotics, without surgery. In cases where the recurrence of inflammation occurs (14 \% of them), surgical treatment is performed (22, 23).

\section{Aim of the study}

The overall aim of this study is to determine role of the hyperbilirubinemia in early triage and diagnosis of complicated versus non-complicated appendicitis in patients following clinical assessment such as the Alvarado Scoring system.S pecific aims of the research

1. To determine sensitivity and specificity of bilirubin levels in early assessment of acute appendicitis.

2.To establish bilirubin level as a standard laboratory marker for diagnosis of appendicitis.

\section{Materials and methods}

\section{Ethics}

The Ethical Committee of the University Clinical Center of Kosovo approved the study protocol (with reference number 1/86/2016). The signed informed 
consent of the patients were obtained from all

subjects that participated in this study.

\section{Inclusion criteria}

1. Patients admitted in emergency ward and surgery unit, clinically suspicious for acute appendicitis (all patients included in this study were operated for acute appendicitis).

2. Patients from 14 years old and above.

\section{Exclusion criteria}

1. Children with abdominal pain younger than 14 years.

2. Patients with liver disease, hepatitis and jaundice.

3. Patients with hemolytic anemia and consequent hyperbilirubinemia.

4. Patients with abdominal trauma injury.

\section{Statistical Analysis}

Statistical analysis was performed by using statistical package SPSS 17.0 version software. All categorized variables were presented as proportion in percentages with their $95 \%$ confidence interval $(95 \% \mathrm{Cl})$. The mean values of all continuous variables will also present with their $95 \% \mathrm{Cl}$. X2analysis or Fisher exact test will perform to test the difference in proportions of qualitative variables between groups. The diagnostic performance of a test used as primary outcomes was evaluated using Receiver Operating Characteristic (ROC) curve analysis. The level $P<0.05$ was consider as the cutoff value for significance.

\section{Results}

A total of 201 subjects with acute appendicitis were enrolled in this study. In all 201 patents appendicitis was the final diagnosis. They were randomized in two groups. Complicated acute appendicitis was found in 136 patients (67.7\%) participating in this study. While 65 patients (32.2\%) were identified with non-complicated appendicitis. The percentage difference is statistically significant with $p<0.05$ ( $p=0.0000$-Difference test) (Graph 1).

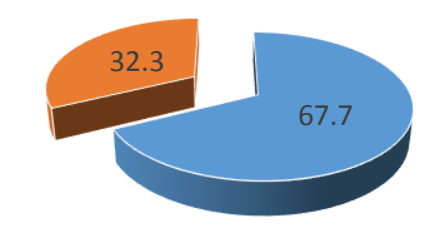

$$
\text { - complicated non-complicated }
$$

Graph 1. Distribution of patients with complicated and non-complicated appendicitis

\section{Age Distribution}

The average age of patients with complicated appendicitis is 30.7 years old, while the average age of patients with non-complicated appendicitis is 21.9 years old (Table no.2). According to the MannWhitney $U$ test, the difference between two groups is statistically significant for $p<0.05$ ( $p=0.000009)$.

\begin{tabular}{l|llll}
$\begin{array}{l}\text { RANK SUM - } \\
\text { GROUP } 1\end{array}$ & RANK SUM - GROUP 2 & $U$ & $Z$ & P-LEVEL \\
\hline 15444,50 & 4856,500 & 2711,500 & 4,428981 & 0,000009
\end{tabular}

Table 2. Difference between age, complicated and non-complicated appendicitis determined by Mann-Whitney U Test $1{ }^{*}$ complicated appendicitis. $2 *$ non-complicated appendicitis

Bilirubin level between two groups of studies 
The average level of total bilirubin in the group with complicated acute appendicitis is $24.9 \mathrm{mg} / \mathrm{l}$, higher than the reference value $(18.8 \mathrm{mg} / \mathrm{L})$. Average value of total bilirubin in the group of non-complicated appendicitis is $14.9 \mathrm{mg} / \mathrm{L}$ and it is in line with the reference value (18,8 mg/L), (Tab.3 and Graph.2). The difference between the average values of total bilirubin according to the Mann-Whitney $U$ test is statistically significant; $p<0.05(p=0.000022)$.

Mean- Mean-2 Valid N-1 ValidN-2 Std.Dev.-1 Std.Dev. - 2

1

\begin{tabular}{l|llllll} 
Bil Level T & 24,9 & 14,9 & 136 & 65 & 19,56050 & 8,04453
\end{tabular}

Table 3. Average value of total bilirubin in complicated and non-complicated group

$1 *$ complicated appendicitis $2 *$ non-complicated appendicitis

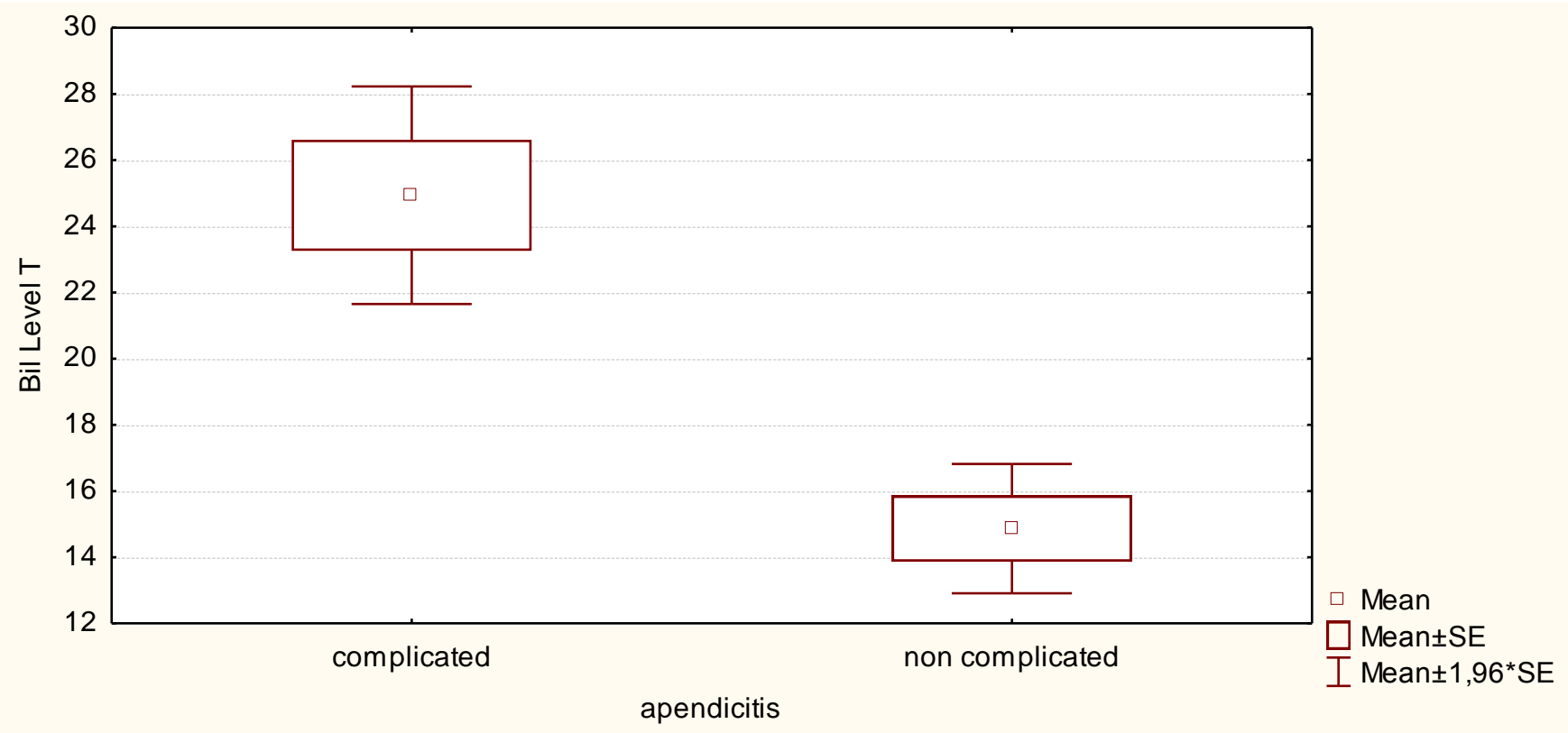

Graph 2. The average value of total bilirubin in complicated and non-complicated appendicitis

Rank Sum - Group 1 Rank Sum - Group $2 \quad U \quad Z \quad$-level

\begin{tabular}{l|lllll} 
Bil Level T & 15373,50 & 4927,500 & 2782,500 & 4,244926 & 0,000022
\end{tabular}

Table 4. Mann-Whitney $U$ Test (total bilirubin and appendicitis)

$1 *$ complicated appendicitis $2 *$ non-complicated appendicitis complicated and non-complicated acute

The accuracy of total bilirubin as a diagnostic test appendicitis, is analyzed in Table 4. From the total (predictor marker) for the detection of early 
number of 201 patients with appendicitis, true positive were 74 patients, false positive 18 . From

109 negative findings, 47 true negative and 62 false negative results.

The accuracy of total bilirubin: sensitivity $54.4 \%$, specificity $72.3 \%$, positive predictive value $80.4 \%$, negative predictive value $43.1 \%$. Total accuracy $60.2 \%$.

ROC analysis shows that total bilirubin participates in establishing the diagnosis in complicated appendicitis with $68.5 \%(p=0,000)$ (good predictor for complicated appendicitis) (Figure 1).

Average value of direct bilirubin in the group of complicated appendicitis is $7.9 \mathrm{mg} /$ Land is higher than the reference value $(5.1 \mathrm{mg} / \mathrm{L})$. The average value of direct bilirubin in the group of noncomplicated appendicitis is $4.8 \mathrm{mg} / \mathrm{L}$ and it is in line with the reference value $(5.1 \mathrm{mg} / \mathrm{L})$. The difference between the average values for direct bilirubin according to the Mann-Whitney $U$ test is statistically significant with the value of $p<0.05(p=0.000251)$, (Table 5).

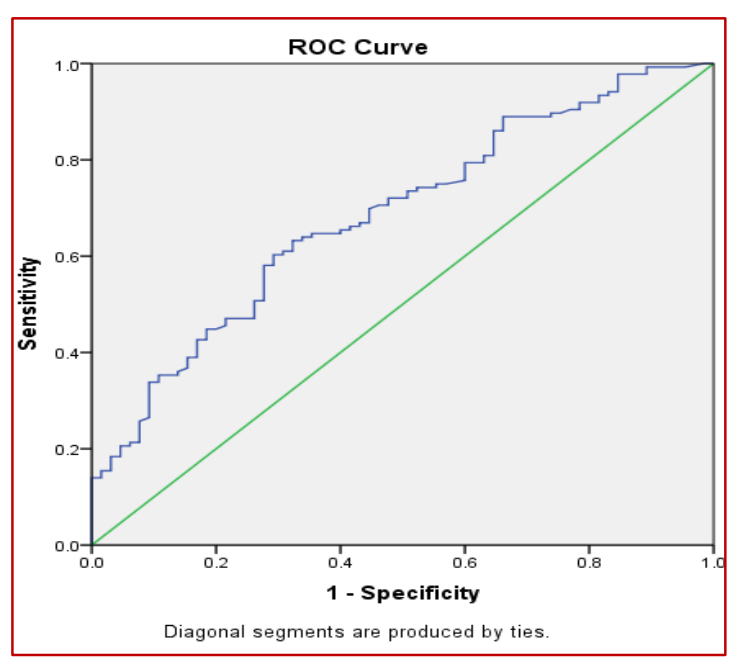

Figure1. ROC curve for total bilirubin as a predictor for complicated appendicitis

\begin{tabular}{|c|c|c|c|c|c|}
\hline & $\begin{array}{l}\text { Rank Sum } \\
\text { - Group } 1\end{array}$ & $\begin{array}{l}\text { Rank Sum - } \\
\text { Group } 2\end{array}$ & $U$ & $Z$ & p-level \\
\hline Bil & 15148,50 & 5152,500 & 3007,500 & 3,661654 & 0,00025 \\
\hline $\begin{array}{r}\text { Level } \\
D\end{array}$ & & & & & 1 \\
\hline
\end{tabular}

Table 5. Direct bilirubin level according to Mann-Whitney U Test

$1^{*}$ complicated appendicitis. $2 *$ non-complicated appendicitis

The accuracy of direct bilirubin as a diagnostic test (predictor marker) for the detection in early complicated and non-complicated appendicitis, is analyzed in Table 20. From 201 patients with acute appendicitis, true positive were 76 , false positive 60. From 65 negative results, 46 were true negative and 19 false negative results. The accuracy of direct bilirubin: sensitivity $80.0 \%$, specifity $43.4 \%$, positive

predictive value $55.9 \%$, negative predictive $70.7 \%$. Total accuracy is $60.7 \%$.

ROC analysis shows that direct bilirubin participates in establishing the diagnosis in complicated 
appendicitis with 68.5\% ( $p=0,000)$, (good predictor for complicated appendicitis) (Figure 2).

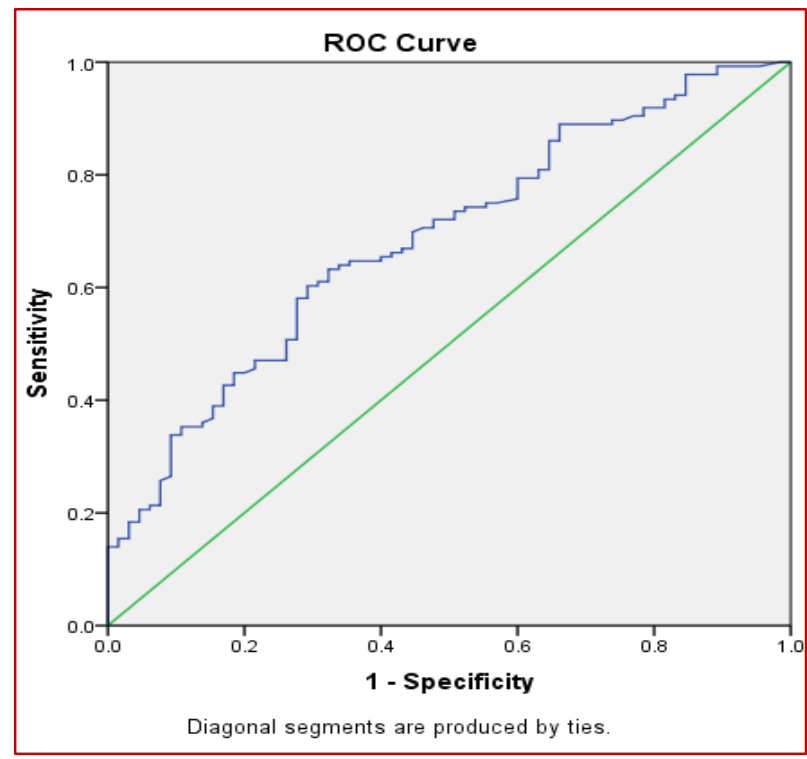

Figure2. ROC curve for direct bilirubin as a predictor for complicated appendicitis

Alvarado scoring model between complicated vs non-complicated appendicitis

According to the Alvarado Score, the largest percentage of patients with complicated appendicitis consist of patients with definitive diagnosis of acute appendicitis, who require a surgical intervention (61.8\%). $31.6 \%$ of them comprise patients with acute appendicitis, and finally, the remaining $6.6 \%$ consist of patients with a possible diagnosis of acute appendicitis.

According to the Alvarado Score, the largest percentage of patients with non-complicated appendicitis consisted of patients with presence of acute appendicitis (49.2\%). The percentage of $33.8 \%$ of the patients is comprised of patients with definitive diagnosis, required surgical intervention, and finally, the percentage of $17.0 \%$ consisted of patients with a possible diagnosis of acute appendicitis based on the Alvarado Score (Graph 3).
The difference in percentage which is registered in two groups of the study in relation with Alvarado Score is statistically significant for $p<0.05(p=0.0002 ; p=0.0158, p=0.0212)$.

\section{\$ 5-6AS $⿴ 7-8$ AS $ه 9-10 A S$}

non complicated

complicated

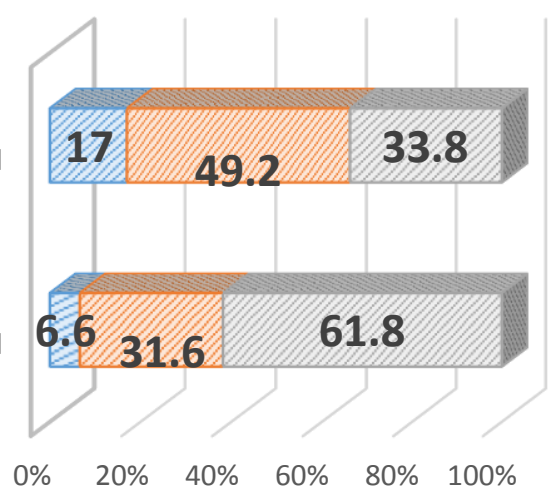

Graph 3. Diagnosis based on the Alvarado Score model

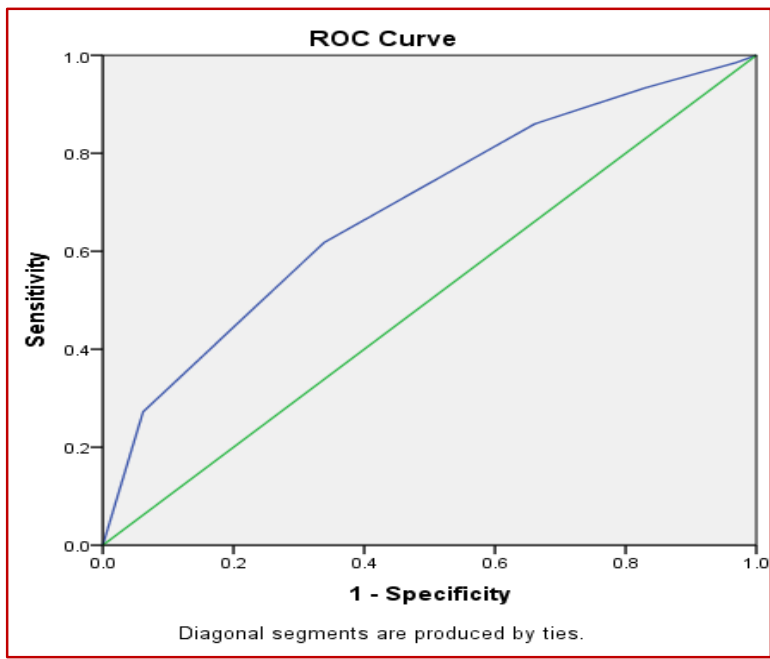

Figure3. ROC curve for Alvarado score as a predictor for complicated appendicitis

ROC analysis shows that Alvarado score participates in establishing the diagnosis for complicated appendicitis with $68.6 \%(p=0,000)$, (good predictor for complicated appendicitis) (Figure 3). 


\section{Disscusion}

Data from our study revealed bilirubin level and Alvarado score as reliable markers in the diagnosis of the complicated versus non-complicated appendicitis.

Diagnostic test accuracy (ROC) in the present study ranged from $68.6 \%$ for bilirubin and Alvarado score. The incidence of acute appendicitis is different, but the prevalence is around 7.5 up to 22 out of 10000 citizens. $(3,24,25)$ Delayed diagnosis and complication are important outcome measures during the surgical evaluation.

In this study, we intended to analyze the laboratory marker such as: bilirubin level total/direct, gender, Alvarado scoring and histopathologic results in patients, divided in two groups with complicated and non-complicated appendicitis.

Complicated appendicitis is defined as gangrenous appendicitis, perforation, abscesses and peritonitis whereas non-complicated appendicitis were phlegmonous and catarrhal appendicitis. In our study, we have analyzed 201 patients with acute appendicitis in which appendectomy was performed.

From the total number of patients that participated in this study $67.7 \%$ or 136 patients were diagnosed with complicated appendicitis and $32 \%$ or 65 patients with non-complicated appendicitis, therefore statistically significant difference was recorded for patients with complicated vs noncomplicated appendicitis.

According to the retrospective cohort study conducted by Serres SK and al, the rate of complication for patients with acute appendicitis was around $23 \%$ in their study (26). Contradictory, in our study, the rate of complications in patients with acute appendicitis were much higher compared to the abovementioned study. This main finding in our study might be partially explained by non-appropriate and over-use of different analgezics during the initial phases of the disease which may mask or mimic clinical appearance and therefore delay the prompt diagnosis of acute appendicitis. Delayed referral from the primary health care as well as limited access to the medical services are among frequent determining factors for the disease outcome.

Statistically significant dependence was recorded between the gender, age and the form of appendicitis. The average age for patients with complicated appendicitis was 30.7 years (mean-1) while in patients with non-complicated appendicitis the average age was 21.9 years (mean-2). Although the majority of the published studies revealed predominantly male gender in acute appendicitis, to our current knowledge, association between the male gender and complicated form of appendicitis was not previously described. Therefore, MannWhitney-U test showed statistically significant difference $(p<0.05)$ regarding the patient gender and form of the acute appendicitis in the present study. $74.3 \%$ of patients with acute complicated appendicitis were male and only $25.7 \%$ were female hence, statistically significant difference was found between males and females and complicated appendicitis $((p<0.05)$

The role of hyperbilirubinemia as a laboratory marker that may contribute in the diagnosis of acute appendicitis has been analyzed in numerous studies (27-29). Different studies, recently have tried to explain the role of hyperbilirubinemia in patient with sepsis and small number of authors have hypothesized the connection between hyperbilirubinemia and acute appendicitis and its complication $(29,30)$.

In our cross-sectional study 201 patients with acute appendicitis were enrolled in total. From the total number of patients that participated in this study, 
$67.7 \%$ of them were patients with complicated acute appendicitis while $32.3 \%$ were patients with non-complicated acute appendicitis. Based on our study, the level of total bilirubin was elevated in the group of patients with complicated appendicitis with average level of bilirubin $24.9 \mathrm{mg} / \mathrm{l}$ and according to the Mann-Whitney $U$ test this result is statistically significant. For direct bilirubin the average value is $7.9 \mathrm{mg} / \mathrm{l}$, also statistically significant. For complicated appendicitis, sensitivity of total bilirubin was $54.4 \%$, specificity 72.3 , positive predictive value 80.4 , negative predictive value 43.1 while global accuracy reaches up to $60.2 \%$. Poras Chaudhary et al, in the prospective study of 50 cases have concluded that bilirubin is an important marker during the diagnosis of appendicitis and complicated appendicitis(31). According to the same results from this study hyperbilirubinemia was present in perforated and gangrenous appendicitis. The level of serum bilirubin reported was above $3 \mathrm{mg} / \mathrm{dl}$, sensitivity and specificity of hyperbilirubinemia in gangrenous appendicitis was $100 \%$ and $92.9 \%$ respectively, with high positive and negative predictive value (72.7\% and $100 \%$, respectively) according to this study(31).

The role of hyperbilirubinemia in revealing complicated or perforative appendicitis was also demonstrated in another study conducted by Khan and co-workers. Reported sensitivity and specificity of the total bilirubin level in predicting the perforative appendicitis according to this study was $88 \%$ and $80 \%$ respectively(32). D'Souza $\mathrm{N}$ et al in their study suggest that hyperbilirubinemia in patients with acute appendicitis and complicated cases of appendicitis had higher specificity compared with WBC and CRP.(33) We have evaluated the accuracy of total bilirubin and according to our study the sensitivity of total bilirubin is $54.4 \%$, specify $72.3 \%$ positive predictive value $80.4 \%$ and negative predictive value $43.1 \%$. The study from D'Souza $\mathrm{N}$ et al, concluded that serum bilirubin in acute appendicitis is marker with higher sensitivity but with low sensitivity.(33) The serum bilirubin analysis with receiver-operating characteristic curve (ROC) in our study have shown that bilirubin marker is good predictor for complicated appendicitis (68.6\%). Based on a study from Andrew Emmanuel et al, where the bilirubin level was analyzed using ROC curve the sensitivity were $57 \%$ and specificity $72 \%$ (34). In 201 patients enrolled in our study, we have concomitantly performed total bilirubin as well as direct bilirubin measurement. In this study statistically, significant difference was found regarding the total bilirubin level in complicated vs non -complicated appendicitis ( $24.9 \mathrm{mg} / \mathrm{L}$ vs $14.9 \mathrm{mg} / \mathrm{L}$, respectively). Statistically significant difference was also found regarding the direct bilirubin measured in our subjects $(7.9 \mathrm{mg} / \mathrm{L}$ vs $4.8 \mathrm{mg} / \mathrm{L})$ between the complicated and non-complicated appendicitis. One of the most interesting findings in the present study is that sensitivity of the total bilirubin for differentiating complicated vs non-complicated appendicitis was only $54.4 \%$ and $80.0 \%$ for direct bilirubin. This way the combination of those two markers can improve clinical diagnosis in Emergency Ward and classify patients with acute need for surgery.

Although PPV was similar for total and direct bilirubin (80.4 vs 70.7), the total accuracy for total and direct bilirubin resulted with 60.2 vs 60.7 respectively.

Therefore, hyperbilirubinemia is strongly suggestive of complicated appendicitis based on the data from the previous studies and in the same line are correspondingly results from the present study. (35) The Alvarado scoring system was used in our study to determine the role of this model in reducing the mismatch diagnosis. According to the ROC analysis 
preformed during our study, Alvarado score is very good predictor in cases of complicated appendicitis with $68.6 \%$. Based on our study the use of the scoring system in patients with suspicion for acute appendicitis ensures high rate of sensitivity and specificity. Also the study from Memon ZA et al, showed that Alvarado scoring system can contribute in decreasing the negative appendectomy.(36).

In this study all appendectomy samples were referred for histopathologic evaluation and diagnosis which also included patient follow-up. Results from our study showed a strong correlation between the primary clinical assessment and final diagnosis.

Hence, gangrenous changes in histopathological examination were found in $99.3 \%$ of complicated appendicitis and phlegmonous changes in $87.7 \%$ of non-complicated cases.

Important finding from the present study is also statistically highly significant correlation between the histopathologic diagnosis and total and direct bilirubin $(p<0.05)$.

To summarize, the above mentioned relationships between each variables used in the study, reveal hyperbilirubinemia and Alvarado scoring system as the most reliable biomarkers for early diagnosis and prognosis of acute appendicitis, pointing out the obvious discriminatory strength of the bilirubin level and scoring system to categorize complicated from non-complicated appendicitis.

\section{Conclusion}

1. Data from the present study found out high rate of complications in patients diagnosed with acute appendicitis in our study sample.

2. Our results demonstrated a strong correlation between the male gender and complicated appendicitis (male $74.3 \%$ vs female $25.7 \%$ ).
3. Hyperbilirubinemia poses moderate diagnostic and prognostic test accuracy principally for the complicated appendicitis (ROC=68.6\%).

4. Combination of total and direct bilirubin can improve clinical diagnosis in Emergency Ward and classify patients with acute need for surgery.

5. Alvarado scoring system is a good diagnostic predictor in complicated appendicitis (ROC=68.6\%).

6. A strong correlation between the clinical diagnosis and histopathological result was evidently demonstrated.

7. Total and direct bilirubin level showed statistically significant correlation with the final histopathological diagnosis $(p<0.05)$.

\section{References}

1.Graham JM, Pokorny WJ, Harberg FJ. Acute appendicitis in preschool age children. Am J Surg. 1980;139(2):247-50.

2.Schwartz SI, Brunicardi FC. Schwartz's principles of surgery. 9th ed. New York: McGraw-Hill, Medical Pub. Division; 2010. xxi, 1866 p. p.

3.Addiss DG, Shaffer N, Fowler BS, Tauxe RV. The epidemiology of appendicitis and appendectomy in the United States. Am J Epidemiol.

1990;132(5):910-25.

4.Bundy DG, Byerley JS, Liles EA, Perrin EM, Katznelson J, Rice HE. Does this child have appendicitis? JAMA. 2007;298(4):438-51.

5.Rabah R. Pathology of the appendix in children: an institutional experience and review of the literature. Pediatr Radiol. 2007;37(1):15-20. 6.Lamps LW. Infectious causes of appendicitis. Infect Dis Clin North Am. 2010;24(4):995-1018, ix-x. 
7.Montgomery EA, Popek EJ. Intussusception, adenovirus, and children: a brief reaffirmation. Hum Pathol. 1994;25(2):169-74.

8.Paik SY, Oh JT, Choi YJ, Kwon KW, Yang WI. Measles-related appendicitis. Arch Pathol Lab Med. 2002;126(1):82-4.

9.Karakus E, Mambet E, Azili MN, Gulhan B, Tiryaki

$\mathrm{T}$, Tezer $\mathrm{H}$. Actinomycosis of the appendix in childhood- an unusual cause of appendicitis. APSP J Case Rep. 2014;5(3):26.

10.Arca MJ, Gates RL, Groner JI, Hammond S, Caniano DA. Clinical manifestations of appendiceal pinworms in children: an institutional experience and a review of the literature. Pediatr Surg Int. 2004;20(5):372-5.

11.Sinha SN, Sinha BN. Appendicular perforation due to Ascaris lumbricoides. J Indian Med Assoc. 1974;63(12):396-7.

12.Rautio M, Saxen H, Siitonen A, Nikku R, Jousimies-Somer H. Bacteriology of histopathologically defined appendicitis in children. Pediatr Infect Dis J. 2000;19(11):1078-83. 13.Kokoska ER, Silen ML, Tracy TF, Jr., Dillon PA, Kennedy DJ, Cradock TV, et al. The impact of intraoperative culture on treatment and outcome in children with perforated appendicitis. J Pediatr Surg. 1999;34(5):749-53.

14. Rink RD, Kaelin CR, Giammara B, Fry DE. Effects of live Escherichia coli and Bacteroides fragilis on metabolism and hepatic p02. Circ Shock. 1981;8(5):601-11.

15.Shander A. Anemia in the critically ill. Crit Care Clin. 2004;20(2):159-78.

16.Cuschieri J, Florence M, Flum DR, Jurkovich GJ, Lin P, Steele SR, et al. Negative appendectomy and imaging accuracy in the Washington State Surgical Care and Outcomes Assessment Program. Annals of surgery. 2008;248(4):557-63.

17.Samuel M. Pediatric appendicitis score. J Pediatr Surg. 2002;37(6):877-81.
18.Lintula H, Pesonen E, Kokki H, Vanamo K, Eskelinen M. A diagnostic score for children with suspected appendicitis. Langenbecks Arch Surg. 2005;390(2):164-70.

19.Kalan M, Talbot D, Cunliffe WJ, Rich AJ. Evaluation of the modified Alvarado score in the diagnosis of acute appendicitis: a prospective study. Ann R Coll Surg Engl. 1994;76(6):418-9. 20.Alvarado A. A practical score for the early diagnosis of acute appendicitis. Annals of emergency medicine. 1986;15(5):557-64. 21.Eriksson S, Granstrom L. Randomized controlled trial of appendicectomy versus antibiotic therapy for acute appendicitis. The British journal of surgery. 1995;82(2):166-9.

22.Styrud J, Eriksson S, Nilsson I, Ahlberg G, Haapaniemi S, Neovius G, et al. Appendectomy versus antibiotic treatment in acute appendicitis. a prospective multicenter randomized controlled trial. World journal of surgery. 2006;30(6):1033-7. 23.Hansson J1 KU, Khorram-Manesh A, Solberg A, Lundholm K. Randomized clinical trial of antibiotic therapy versus appendicectomy as primary treatment of acute appendicitis in unselected patients. Br J Surg 2009 May;96(5):473-81 doi: 101002/bjs6482. 2009.

24.Al-Omran M, Mamdani M, McLeod RS. Epidemiologic features of acute appendicitis in Ontario, Canada. Canadian journal of surgery Journal canadien de chirurgie. 2003;46(4):263-8. 25.Lee JH, Park YS, Choi JS. The epidemiology of appendicitis and appendectomy in South Korea: national registry data. Journal of epidemiology. 2010;20(2):97-105.

26.Serres SK, Cameron DB, Glass CC, Graham DA, Zurakowski D, Karki M, et al. Time to Appendectomy and Risk of Complicated Appendicitis and Adverse Outcomes in Children. JAMA pediatrics. 2017;171(8):740-6. 
27.D'Souza N, Karim D, Sunthareswaran R. Bilirubin; a diagnostic marker for appendicitis. International Journal of Surgery. 2013;11(10):1114-7.

28.Estrada JJ, Petrosyan M, Barnhart J, Tao M, Sohn

$\mathrm{H}$, Towfigh $\mathrm{S}$, et al. Hyperbilirubinemia in appendicitis: a new predictor of perforation. Journal of gastrointestinal surgery : official journal of the Society for Surgery of the Alimentary Tract. 2007;11(6):714-8.

29.Giordano S, Pääkkönen M, Salminen P, Grönroos $J M$. Elevated serum bilirubin in assessing the likelihood of perforation in acute appendicitis: $A$ diagnostic meta-analysis. International Journal of Surgery. 2013;11(9):795-800.

30.Nesseler N, Launey Y, Aninat C, Morel F, Mallédant $Y$, Seguin P. Clinical review: The liver in sepsis. Critical Care. 2012;16(5):235-.

31.Poras Chaudhary AK, Neeraj Saxena, Upendra C. Biswal. Hyperbilirubinemia as a predictor of gangrenous/perforated appendicitis: a prospective study. Ann Gastroenterol 2013; 26(4): 325-331.

2013.

32.Dr. A. Q. Khan1 DAP, Dr. Praful Pawar 3. Role of Hyperbilirubinemia as a Diagnostic

Predictor of Appendicular Perforation. International Journal of Science and Research (IJSR). 2012;ISSN (Online): 2319-7064.

33.D'Souza N, Karim D, Sunthareswaran R. Bilirubin; a diagnostic marker for appendicitis. International journal of surgery (London, England).

2013;11(10):1114-7.

34.Emmanuel A, Murchan P, Wilson I, Balfe P. The value of hyperbilirubinaemia in the diagnosis of acute appendicitis. Annals of The Royal College of Surgeons of England. 2011;93(3):213-7. 35.Radhakrishna V, M. Patil S, S. Patil R. Evaluation of hyperbilirubinemia as an innovative diagnostic marker for acute appendicitis and its role in the prediction of appendicular perforation2017. $1662 \mathrm{p}$.
36.Memon ZA, Irfan S, Fatima K, Iqbal MS, Sami W. Acute appendicitis: diagnostic accuracy of Alvarado scoring system. Asian journal of surgery.

2013;36(4):144-9. 